concerns both eyes; whether this is to be classed as congenital or acquired can only be decided by a careful study of cases of ectopia lentis rendered aphakic very early in life and optically corrected, e.g. within the first year of life. If the child is found to develop normal acuity of vision the amblyopia may be classed as acquired; otherwise as congenital. If the evidence is for the amblyopia being acquired, the study of older cases rendered aphakic and corrected will reveal up to what age the macular region retains the capacity to preponderate and attain normal acuity.

\title{
REFERENCES
}

Parsons.- " Pathology of the Eye," Vol. III, p, 809.

Claud Worth.- " Squint," 3rd edition, 1906.

\section{A CASE OF CONGENITAL MIOSIS}

BY

\author{
Thomas H. Cresswell, D.O.(Oxon.)
}

LiNCOLN

A RECENT paper by S. Holth and O. Berner on congenital miosis appeared in this journal (Brit. Jl. of Ophthal., p. 401, 1923). A patient in whom this abnormality was present has recently come under my observation at the County Hospital, Lincoln, and was shown at a meeting of the Midland Ophthalmological Society.

The patient was a man of 57 years of age, one of a family of seven. He knew that his eyes were peculiar and also that he was the only member of his family so affected. He added that when nine months old he suffered from smallpox and that his mother had suggested that the condition of his eyes might be due to this disease. At the same time that he had smallpox he had had several severe abscesses on the top of the head. These have left several deep star-shaped scars into which it is possible to insert the tip of the finger and which are adherent to the calvarium. The possibility of these scars being the result of specific gummatous periostitis has not been lost sight of, but receives no support from the patient's family and personal history or general condition. He had always considered that he had good sight, had no difficulty in going about at night and had never suffered from headaches.

On examination the pupils did not react to light nor to convergence. Seen through a loupe there was possibly a very faint movement of the pupillary margin on exposure to a bright light. Both pupils were roughly circular in shape. Their sizes with and without mydriatics were as follow: 


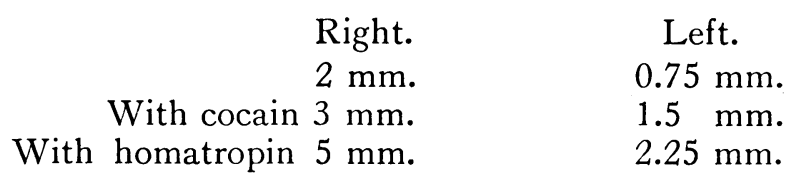

When the pupils were dilated the media appeared clear and no pigment deposits were visible on the lens capsule.

Hypermetropia of about 2.5D was present in both eyes and the vision with this correction was $6 / 6$ in each eye. Small print could be read without the aid of any glass.

The anterior chambers were shallow but the tension was normal and the fields for white were full.

Each iris appeared to consist of a thin membrane made up of closely set radial fibres of varying shades of light green. The

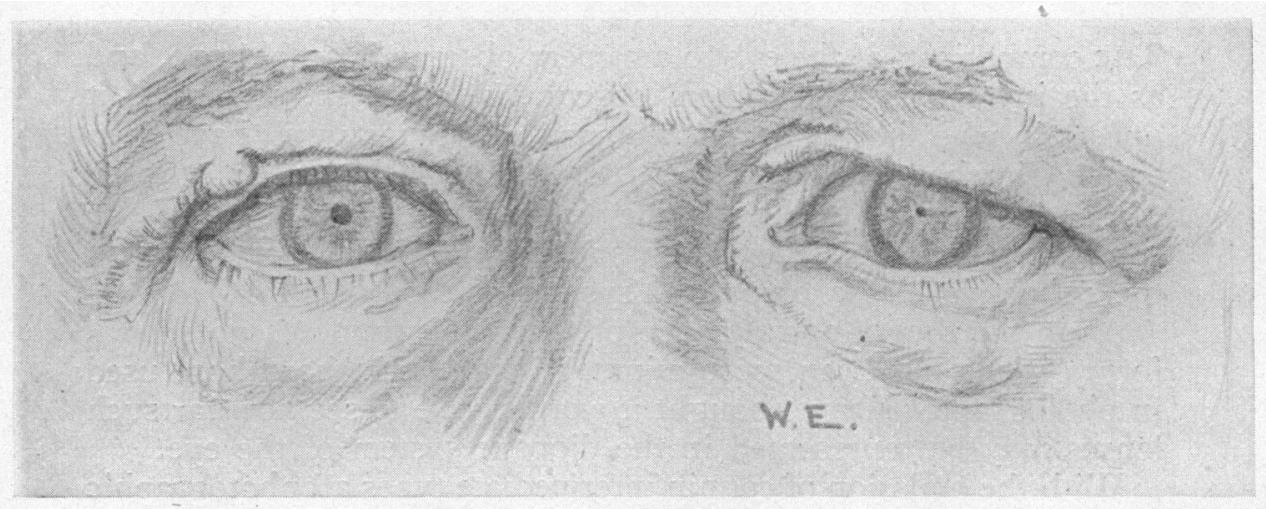

fibres themselves were straight and not undulating. Resting on the surface and clearly dividing it into pupillary and ciliary zones was the circulus iridis minor. The circulus was of a bright yellowish brown colour, while the pupillary zone was overlaid with structureless splodges of pigmented material. These splodges were quite thin, permitting the radial fibres to be seen through them, but were sufficiently marked to give the pupillary zone a brilliant yellowish brown colouration. External to the circulus were less marked intermittent splodges of similar material and colour laid down to form spokes or concentric circles. These spokes or concentric circles did not reach quite to the periphery of the iris; their arrangement was regular and similar in the two eyes, and they served to give the irides what little relief they possessed. No trace of contraction folds could be seen on the left iris before or after dilatation. On the right one, however, a slight fold could be seen on the outside which became more marked with dilatation. 
It appeared incomplete but formed a considerable segment of a circle.

The above description applies chiefly to the left iris. The departure from the normal was less marked in the right eye. The writer believes this to be a case of congenital miosis of varying degree in the two eyes, and due probably, having regard to the findings of Holth and Berner, to developmental faults in the dilator muscle.

\title{
THE EYE AND PHOTOGRAPHIC LENSES.
}

\author{
BY \\ V. C. VeRBITZKY \\ ASSISTANT IN THE UNIVERSITY OPHTHALMOLOGICAL CLINIC, ODESSA
}

THE comparison of the eye to a camera obscura is an old one, and as the inventor of the camera obscura is unknown, so also is it uncertain who first made the comparison. It may well have been either Giambaptista della Porta, Leonardo da Vinci, or even an earlier observer, the Benedictine Friar, Dom Ponrince(1). The comparison can only have been superficial and did not deal with the refractive media or optical system of the eye.

As in the theory and practice of optical instruments no special form of lens has been more minutely dealt with than those used in photography I have thought it worth while to see how far such lenses may be represented in the dioptric system of the eye.

With the omission of certain intermediate types all photographic lenses may be divided into four principal groups $^{(2,3)}$.

(1) Portrait lenses. - These give maximum light transmission and have apertures $f / 2.5, f / 3, f / 4.5$. In this form of lens the number of refractive surfaces in contact with air is either 8 or 6 .

(2) Universal lenses. - The maximum light transmission through this type of lens approaches that of the first group, the minimum amount that of the following one. They have apertures of $f / 4.5, f / 7, f / 9, f / 12$. The number of refracting surfaces is either 6 or 4 .

(3) Wide-angled lenses.-These have apertures of $f / 12, f / 18$, $f / 30$. The number of refractive surfaces is not more than 4 .

(4) Simple landscape lenses.-These have a relative aperture of $f / 12$ and lower, and 2 refracting surfaces.

The corrected schematic eye of Gullstrand ${ }^{(4)}$, which I consider one of the best schematic eyes hitherto suggested, has 6 refractive surfaces and a relative aperture in the "working pupil" ( $4 \mathrm{~mm}$.) of $f / 5.7$. In the dilated pupil $(6 \mathrm{~mm}$.) the aperture is $f / 3.8$, and in the contracted pupil $(2 \mathrm{~mm}$.), $f / 11.4$. 